\title{
STUDI KEBERADAAN JENTIK NYAMUK Aedes sp. BERDASARKAN KARAKTERISTIK TEMPAT PENAMPUNGAN AIR DI KELURAHAN TUNGKAL III, KUALA TUNGKAL, JAMBI
}

\author{
Tiana Novrianti ${ }^{1}$, Emilia Chandra ${ }^{2 *}$ \\ ${ }^{1,2}$ Department of Environmental Health, Poltekkes Kemenkes Jambi
}

\section{Artikel Info :}

Received 2 Agustus 2020

Accepted 14 September 2020

Available online 30 April

2021

Editor: Amrul Hasan

Keyword :

Larvae, Aedes sp, bionomic, $D H F$

Kata kunci :

Jentik Aedes sp, TPA, DBD, bionomik

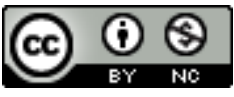

Ruwa Jurai: Jurnal

Kesehatan Lingkungan is

licensed under a Creative

Commons Attribution-

NonCommercial 4.0 International

License.

\begin{abstract}
Tanjung Jabung Barat is a tidal area and is one of the endemic areas for dengue fever in South Sumatra. The highest cases were in the Kuala Tungkal Health Center area, especially in Tungkal III Village. This study aimed to determine the characteristics of the container which Aedes sp. prefer as breeding places. The research was conducted using visual methods inside and outside the home and identified the characteristics of each landfill. The results showed that 54.5\% (36 out of total 66 houses were inspected) and 14.9\% (57 of 381 TPA inspected) found Aedes sp. Based on its characteristics, the Aedes sp. prefer to lay eggs in TPA made of plastic (16.0\%), drum-type (21.3\%), and without cover (18.0\%). Based on water sources, larva Aedes sp. more common in landfills that collect rainwater (26.0\%) and outside the house (19.1\%). Limited clean water sources encourage people to use large TPAs to collect rainwater. The use of abate, periodic larva monitoring, and increasing public knowledge are actions that must be taken.
\end{abstract}

\begin{abstract}
Tanjung Jabung Barat merupakan daerah pasang surut dan merupakan salah satu wilayah endemik penyakit DBD di Sumatera Selatan. Kasus tertinggi di wilyah Puskesmas Kuala Tungkal, terutama di Kelurahan Tungkal III. Penelitian bertujuan untuk mengetahui karakteristik TPA yang disukai nyamuk Aedes sp sebagai tempat perindukan. Penelitian dilakukan dengan metode visual di dalam dan di luar rumah, serta mengidentifikasi karakteristik setiap TPA. Hasil penelitian mendapatkan sebanyak 54,5\% (36 dari 66 rumah diperiksa) dan 14,9\% (57 dari 381 TPA diperiksa) ditemukan jentik Aedes sp. Berdasarkan karakteristiknya, nyamuk Aedes sp. lebih suka bertelur di TPA yang terbuat dari bahan plastik (16,0\%), jenis drum (21,3\%), dan tanpa penutup (18,0\%). Sedangkan berdasarkan sumber air, jentik Aedes sp. lebih banyak ditemukan pada TPA yang menampung air hujan (26,0\%), dan berada di luar rumah $(19,1 \%)$. Keterbatasan sumber air bersih mendorong masyarakat menggunakan TPA berukuran besar untuk menampung air hujan. Penggunaan abate, pemantauan jentik berkala, dan meningkatkan pengetahuan masyarakat menjadi tindakan yang harus dilakukan.
\end{abstract}

${ }^{*}$ Corresponding author : Emilia Chandra

Department of Environmental Health, Poltekkes Kemenkes Jambi

J. H. Agus Salim No.09, Paal Lima, Kec. Kota Baru, Kota Jambi, Jambi 36128.

Email : emilea@yahoo.co.id

\section{PENDAHULUAN}

Penyakit Demam Berdarah Dengue (DBD) sampai saat ini merupakan salah satu masalah kesehatan di Indonesia yang cenderung meningkat dari tahun ke tahun, baik jumlah pasien maupun luas penyebarannya. Pada tahun 2018, jumlah penderita DBD yang dilaporkan sebanyak 65.602 orang, dengan kematian sebanyak 68.407 orang. Sedangkan jumlah kabupaten/kota terjangkit DBD sebanyak 440 (85,6\%), meningkat dibandingkan tahun 2017, dari 434 (84,4\%) (Kementerian Kesehatan RI, 2019).

Penderita DBD di Provinsi Jambi tersebar di 11 Kabupaten/Kota, salah satunya di Kabupaten Tanjung Jabung Barat. Sepanjang tahun 2018, jumlah penderita DBD sebanyak 221 orang, dengan satu orang meninggal. Jika dibandingkan 
tahun 2017, jumlah terjadi peningkatan jumlah kasus lebih dari dua kali lipat, dari 93 kasus (Dinkes Kab. Tanjung Jabung Barat, 2019).

Salah satu faktor yang diduga berperan terhadap tingginya kasus DBD di Tanjung Jabung Barat adalah karakteristik daerah pasang surut dan sulit mendapatkan air bersih. Kekurangan supply air bersih mendorong masyarakat memanfaatkan air hujan sebagai sumber air bersih untuk kebutuhan sehari-hari. Akibatnya, setiap rumah menyediakan banyak tempat penampungan air (TPA) sebagai tempat menyimpan air bersih. Penggunaan TPA ukuran besar berpotensi sebagai tempat perkembang-biakan Aedes $s p$.

Kasus DBD di Tanjung Jabung Barat tersebar di 16 Puskesmas, tertinggi di wilayah Puskesmas I Kuala Tungkal, sebanyak 43 kasus (tahun 2017). Dari empat kelurahan yang menjadi wilayah kerja Puskesmas I Kuala Tungkal, Kelurahan Tungkal III merupakan wilayah dengan jumlah kasus DBD tertinggi, sebanyak 15 kasus (Maret-Oktober 2018). Hasil survey awal, diketahui bahwa jenis bahan TPA sangat bervariasi, yaitu bahan plastik, semen, dan kaleng atau besi.

Beberapa penelitian telah melaporkan temuannya tentang karakteristik tempat perindukan nyamuk Ae.aegypti. Penelitian di Provinsi Nusa Tenggara Timur mendapatkan bahwa TPA yang paling potensial sebagai tempat perindukan nyamuk berada di luar rumah (57,89\%) dan terbuat dari bahan logam/kaleng (50,0\%) (Wahab and Wanti, 2019). Laporan lain mendapatkan jentik Ae.aegypti lebih banyak di TPA dalam rumah $(60,0 \%)$ dan terbuat dari plastik (56,52\%) (Gafur and Saleh, 2015). Sedangkan berdasarkan karakteristik wilayah, jentik Aedes $s p$ di daerah endemis paling banyak terdapat di TPA berbahan besi, dan di daerah bebas di TPA dari plastik (Wanti and Menofeltus, 2014).

Penelitian bertujuan untuk mengetahui karakteristik TPA yang disukai nyamuk Aedes $s p$ sebagai tempat perindukan.

\section{METODE}

Penelitian bersifat deskriptif dengan metode (spot survey) untuk mengetahui karakteristik TPA yang disukai nyamuk Aedes sp sebagai tempat perindukan. Penelitian dilaksanakan di RT 04 Kelurahan Tungkal III, Kuala Tungkal pada bulan Februari-April 2019.
Populasi penelitian adalah seluruh rumah yang berada di RT 04 Kelurahan Tungkal III Kuala Tungkal, sebanyak 66 rumah. Pada penelitian ini dilakukan pengamatan terhadap seluruh rumah, dan seluruh TPA yang terdapat di dalam dan luar rumah. Penelitian dibantu oleh 2 orang surveyor yang mengamati jentik di setiap TPA. Instrumen yang digunakan berupa lembar observasi/ checklist.

\section{HASIL}

Dari 71 rumah yang ada di RT 04 Kelurahan Tungkal III, sebanyak 66 rumah telah diperiksa. Tiga rumah menolak untuk diperiksa dan dua rumah lainnya tidak dapat ditemui hingga akhir pengumpulan data.

Dari 66 rumah yang diperiksa terdapat 381 TPA. Rumah yang positif terdapat jentik Aedes $s p$ sebanyak 36 rumah (54,5\%), dan TPA positif jentik Aedes sp. sebanyak 57 buah (14,9\%).

Hasil penelitian (Tabel 1) mendapatkan bahwa jentik Aedes sp lebih banyak ditemukan di drum (21,3\%), dan TPA dari bahan plastik (16,0\%). Sebanyak $18,0 \%$ TPA yang tidak memiliki tutup ditemukan jentik Aedes sp. Jentik lebih banyak ditemukan di TPA luar rumah $(19,1 \%)$, pada penampungan air hujan $(26,0 \%)$.

\section{PEMBAHASAN}

Hasil survei jentik menunjukkan bahwa tingkat kepadatan jentik relatif tinggi (54,5\%). Walaupun pada penelitian ini tidak dilakukan identifikasi jentik Ae.aegypti, namun dari angka tersebut telah menunjukkan gambaran kepadatan jentik di lokasi penelitian, dan berisiko terjadi penyebaran DBD. WHO menyatakan daerah sensitif dan KLB DBD jika nilai Houses Index (HI) lebih dari 5\% (World Health Organization, 2011, 1997). Angka Bebas Jentik (ABJ) di bawah 95\%, menunjukkan tingginya kepadatan jentik dan berisiko terjadinya penularan DBD (Kemenkes, 2010).

Hasil pemeriksaan juga mendapatkan bahwa karakteristik TPA yang bervariasi, baik dari bahan, jenis, kondisi penutup, sumber air dan letak TPA. Karakteristik yang menonjol sebagai tempat perindukan nyamuk Aedes $s p$. adalah TPA yang berada di luar rumah, terbuat dari bahan plastik, tidak memiliki tutup, dan digunakan untuk menampung air hujan. 
Tabel 1 Persentase keberadaan jentik Aedes $s p$ berdasarkan bahan TPA

\begin{tabular}{|c|c|c|c|c|c|}
\hline \multirow{2}{*}{ Variabel } & \multirow{2}{*}{ Diperiksa } & \multicolumn{4}{|c|}{ Hasil Pemeriksaan } \\
\hline & & Positif & $\%$ & Negatif & $\%$ \\
\hline \multicolumn{6}{|l|}{ Bahan } \\
\hline Semen & 72 & 8 & 11,1 & 64 & 88,9 \\
\hline Plastik & 307 & 49 & 16,0 & 258 & 84,0 \\
\hline Kaleng & 2 & 0 & 0,0 & 2 & 100,0 \\
\hline \multicolumn{6}{|l|}{ Jenis TPA } \\
\hline Bak Mandi & 51 & 7 & 13,7 & 44 & 86,3 \\
\hline Ember & 171 & 22 & 12,9 & 149 & 87,1 \\
\hline Bak wc & 18 & 1 & 5,6 & 17 & 94,4 \\
\hline Drum & 127 & 27 & 21,3 & 100 & 78,7 \\
\hline Tendon air & 11 & 0 & 0,0 & 11 & 100,0 \\
\hline Jerigen & 3 & 0 & 0,0 & 3 & 100,0 \\
\hline \multicolumn{6}{|l|}{ Penutup } \\
\hline Tanpa Penutup & 245 & 44 & 18,0 & 201 & 82,0 \\
\hline Ada Penutup & 136 & 13 & 9,6 & 123 & 90,4 \\
\hline \multicolumn{6}{|l|}{ Sumber air } \\
\hline Air Hujan & 154 & 40 & 26,0 & 114 & 74,0 \\
\hline Air PDAM & 227 & 17 & 7,5 & 210 & 92,5 \\
\hline \multicolumn{6}{|l|}{ Lokasi } \\
\hline Dalam Rumah & 240 & 30 & 12,5 & 210 & 87,5 \\
\hline Luar Rumah & 141 & 27 & 19,1 & 14 & 9,9 \\
\hline
\end{tabular}

1. Keberadaan jentik nyamuk Aedes sp berdasarkan bahan TPA

Berdasarkan hasil penelitian (Tabel 1) menunjukan bahwa bahan TPA yang paling banyak terdapat jentik adalah bahan plastik (16,0\%). Mayoritas warga di lokasi penelitian banyak menggunakan plastik sebagai bahan dasar TPA, karena mudah ditemui, murah dan tahan karat. Menurut Gafur, bahan dasar plastik merupakan bahan yang paling banyak dan mudah ditemukan di pasar, selain harganya yang relatif murah (Gafur and Saleh, 2015).

Berdasarkan kondisinya, sebagian besar TPA berbahan dasar plastik terlihat kotor. Menunjukkan rendahnya perilaku masyarakat dalam membersihkan dan menguras TPA, sehingga berpeluang menjadi tempat perindukan nyamuk. Kesulitan air bersih menjadi alasan yang dikemukakan oleh sebagian besar rumah tangga.

Hasil penelitian ini sejalan dengan penelitian yang di lakukan oleh Damanik, D yang mendapatkan 19 dari 36 TPA yang postif jentik Ae.aegypti terbuat dari bahan dasar plastik (Damanik, 2012). Hasil penelitian yang dilakukan oleh Novelani di Kelurahan Utan Kayu Jakarta juga menyatakan bahwa sebagian besar larva ditemukan pada wadah yang terbuat dari bahan plastik $(55,6 \%)$, dan sisanya dari bahan keramik (25,0\%) dan semen (19,4\%) (Novelani, 2007).

Banyaknya jenis Bahan TPA plastik yang digunakan di RT. 04 Kelurahan Tungkal III sebagai TPA, perlu mendapat perhatian khusus sehingga tidak berpeluang sebagai tempat perindukan nyamuk Aedes sp. Menguras dan melakukan pembersihan TPA dengan cara menyikat bagian dinding secara teratur merupakan salah satu cara fisik dalam pemberantasan jentik nyamuk Ae.aegypti. TPA harus dikuras dan dibersihkan minimal seminggu sekali agar nyamuk tidak berkembang biak (Kementerian Kesehatan RI, 2013).

Penggunaan bubuk abate (temephos) menjadi pilihan untuk TPA berukuran besar atau di daerah sulit air yang tidak mungkin dilakukan pengurasan (Wahab and Wanti, 2019; Yushananta and Ahyanti, 2014).

2. Keberadaan jentik nyamuk Aedes $s p$ berdasarkan jenis TPA

Hasil penelitian menemukan bahwa jentik Aedes sp lebih menyukai drum sebagai tempat perindukan (21,3\%), dibandingkan bak mandi/wc atau ember. Hal ini disebabkan kondisi lokasi penelitian yang sulit mendapatkan air bersih, 
sehingga masyarakat menggunakan TPA berukuran besar untuk menampung dan menyimpan air untuk kebutuhan jangka panjang. Penggunaan drum sebagai TPA menjadi pilihan masyarakat mengingat volume air yang dapat ditampung.

Penggunaan TPA dengan volume besar, mengakibatkan air yang ada di dalamnya berada cukup lama serta keengganan untuk menguras. Sejalan dengan Knox et al (dalam Fock and Alexander, 2006), terdapat hubungan antara volume TPA dengan jumlah jentik yang dihasilkan. TPA dengan volume besar ( $>50$ liter) berpotensi menjadi tempat perindukan Aedes $s p$, dan secara epidemiologi mempunyai arti yang penting (Focks and Alexander, 2007). Hasil penelitian ini juga sejalan dengan Gafur dan Saleh (2015), jenis TPA yang paling banyak ditemukan jentik Aedes aegypti adalah gentong dan drum (Gafur and Saleh, 2015).

\section{Keberadaan jentik nyamuk Aedes sp berdasarkan keberadaan penutup}

Hasil penelitian mendapatkan bahwa TPA tanpa penutup lebih banyak ditemukan jentik Aedes sp (18,0\%). Menurut Hasyimi dkk (2009), ketersediaan TPA yang terbuka menyebabkan nyamuk bebas masuk ke dalam TPA untuk berkembang biak (Hasyimi et al., 2009).

Hasil penelitian ini sejalan dengan penelitian yang dilakukan oleh Gafur dan Saleh (2015), bahwa TPA yang memiliki tutup, paling sedikit ditemukan jentik. Bahkan di daerah yang semua TPA memiliki tertutup rapat, tidak ditemukan jentik. Kondisi TPA yang terbuka atau tidak tertutup rapat, akan memudahkan nyamuk untuk masuk dan bertelur (Gafur and Saleh, 2015)..

Jenis TPA yang biasanya tanpa penutup adalah bak mandi, bak wc, ember, dan drum. Berdasarkan hasil observasi, sebagai besar masyarakat menggunakan drum yang dipotong menjadi dua bagian, sehingga tidak memiliki tutup.

\section{Keberadaan jentik nyamuk Aedes $s p$ berdasarkan sumber air}

Berdasarkan hasil penelitian, TPA untuk menampung air hujan merupakan tempat yang paling banyak ditemukan jentik nyamuk Aedes sp
(26,0\%). Banyaknya jentik Aedes sp pada air hujan dipengaruhi kondisi air yang bersih, jernih, dan $\mathrm{pH}$ normal. Pada penampungan air PDAM, kualitas fisik air terlihat keruh, lengket dan terasa kesat. Kondisi fisik air diduga mempengaruhi ketertarikan nyamuk Aedes sp untuk meletakkan telurnya. Nyamuk Ae.aegypti lebih suka meletakkan telurnya pada air yang bersih, jernih, dan tidak kontak langsung dengan tanah (Wahyuningsih et al., 2017). Hasil penelitian ini sejalan dengan Sudibyo dkk (2009), terdapat hubungan yang sangat erat antara tingkat kekeruhan air dengan jumlah larva Aedes aegypti $(R=0,976)$. Air yang jernih lebih banyak terdapat jentik Ae.aegypti (74,5\%) (Soedibyo, 2012).

Banyaknya masyarakat yang menggunakan TPA untuk menampung air hujan dipengaruhi oleh kondisi lingkungan yang sulit air bersih. Kualitas air PDAM yang kurang baik menjadi faktor yang ikut berkontribusi terhadap penggunaan air hujan. Untuk mengurangi kekeruhan, biasanya masyarakat mengendapkan air PDAM sebelum digunakan. Lamanya waktu pengendapan serta penggunaan TPA tanpa tutup, menjadi penyebab timbulnya tempat perindukan nyamuk.

Kualitas dan kuantitas air yang tidak memenuhi kebutuhan masyarakat menjadi faktor yang mendorong penggunaan TPA dalam jumlah banyak serta ukuran besar. Penggunaan TPA dengan volume besar dapat menjamin ketersediaan air bersih dalam waktu yang lama. Namun di sisi lain, penggunaan TPA berukuran besar akan mengurangi peluang untuk dibersihkan. Upaya yang dapat dilakukan untuk pengendalian yaitu melengkapi TPA dengan tutup secara rapat, memberikan tutup jaring (nett) sehingga masih memungkinkan masuknya air hujan, serta penggunaan bubuk abate.

Upaya peningkatan pengetahuan masyarakat dalam pengendalian penyakit DBD juga perlu dilakukan. Meningkatnya pengetahuan dan pemahaman masyarakat diharapkan dapat mendorong terjadinya perubahan perilaku dalam pemberantasan vektor. Perlu ditanamkan perilaku masyarakat untuk selalu melakukan kegiatan pemberantasan sarang nyamuk, agar perkembangbiakan nyamuk dapat dicegah (Ekaputra et al., 2013; Hasan and Ayubi, 2007). Upaya menggerakkan masyarakat dapat 
dilakukan oleh instansi terkait dengan tindakan efektif berupa memasang papan informasi di tempat-tempat strategis (Yulianti, 2013).

\section{Keberadaan jentik nyamuk Aedes $s p$ berdasarkan letak TPA}

Hasil penelitian mendapatkan bahwa TPA yang terletak di luar rumah lebih banyak yang positif jentik (30\%), dibandingkan di dalam rumah. Hasil ini menunjukkan bahwa TPA yang terletak di luar rumah lebih berisiko menjadi tempat perkembangbiakan nyamuk Aedes $s p$. Tingginya keberadaan jentik di TPA luar rumah diduga dari nyamuk Aedes albopictus. Nyamuk Aedes albopictus lebih banyak ditemukan di luar rumah, karena termasuk species nyamuk hutan yang beradaptasi dengan lingkungan manusia. Aedes albopictus lebih suka berkembangbiak di TPA luar rumah (Kementerian Kesehatan RI, 2013).

Penelitian ini sejalan dengan hasil sebelumnya, bahwa TPA di luar rumah lebih produktif sebagai tempat perindukan nyamuk, karena sebagian besar TPA di luar rumah memiliki volume yang relatif besar untuk penyimpanan air hujan (Wanti and Menofeltus, 2014). Kondisi ini harus diperhatikan terutama pada saat musim hujan, karena tempat perindukan Ae.aegypti di luar rumah akan lebih banyak selama musim hujan. Salah satu faktor lingkungan yang sangat berperan terhadap keberadaan jentik adalah curah hujan (Rusli and Yushananta, 2020; Yushananta and Ahyanti, 2014).

\section{SIMPULAN}

Hasil penelitian mendapatkan sebanyak 36 dari 66 rumah yang diperiksa (54,5\%) ditemukan jentik Aedes sp. Sebanyak 14,9\% TPA yang diperiksa positif terdapat jentik. Berdasarkan karakteristiknya, nyamuk Aedes sp. lebih banyak ditemukan di TPA untuk menampung air hujan (26,0\%), dan berada di luar rumah (19,1\%). Aedes $s p$ juga lebih menyukai TPA yang terbuat dari bahan plastik $(16,0 \%)$, jenis drum $(21,3 \%)$, dan tanpa penutup (18,0\%). Keterbatasan sumber air bersih mendorong masyarakat menggunakan TPA berukuran besar untuk menampung air hujan. Penggunaan abate, pemantauan jentik berkala, dan meningkatkan pengetahuan masyarakat menjadi tindakan yang harus dilakukan.

\section{DAFTAR PUSTAKA}

Damanik, D.D., 2012. Tempat Perindukan Yang Paling Disenangi Nyamuk Aedes aegypti Berdasarkan Jenis Sumber Air.

Dinkes Kab. Tanjung Jabung Barat, 2019. Profil Kesehatan Kabupaten Tanjung Jabung Barat Tahun 2018, 1st ed. Kuala Tungkal.

Ekaputra, I.B., Ani, L.S., Suastika, K., 2013. Analisis faktor-faktor yang berhubungan dengan keberadaan jentik Aedes aegypti di Puskesmas III Denpasar Selatan. Public Health and Preventive Medicine Archive 1, 145.

Focks, D., Alexander, N., 2007. Multicountry study of Aedes aegypti pupal productivity survey methodology: Findings and recommendations.

Gafur, A., Saleh, M., 2015. Hubungan Tempat Penampungan Air dengan Keberadaan Jentik Aedes aegypti di Perumahan Dinas Type E Desa Motu Kecamatan Baras Kabupaten Mamuju Utara. HIGIENE: Jurnal Kesehatan Lingkungan 1, 93-99.

Hasan, A., Ayubi, D., 2007. Correlation between behavior of combating mosquitoes breeding sites with incidence of Dengue Haemorrhagic Fever in Bandar Lampung Municipality, Indonesia. Kesmas 2, 86-90.

Hasyimi, M., Harmany, Pangestu, 2009. TempatTempat Terkini yang Disenangi Untuk Perkembangbiakan Vektor Demam Berdarah. Media Litbang Kesehatan XIX, 71-76.

Kemenkes, P., 2010. BULETIN DBD. Pusat data dan Informasi, Kementerian Kesehatan RI 2.

Kementerian Kesehatan RI, 2013. Buku Saku Pengendalian Demam Berdarah Dengue, Jakarta: Kemenkes RI.

Kementerian Kesehatan RI, 2019. Profil Kesehatan Indonesia 2018 [Indonesia Health Profile 2018].

Novelani, 2007. Studi Habitat dan Perilaku Menggigit Nyamuk Aedes serta kaitannya dengan kasus Demam Berdarah di Kelurahan Utan Kayu Jakarta Timur IPB. Institut Pertanian Bogor.

Rusli, Y., Yushananta, P., 2020. Climate variability and dengue hemorrhagic fever in Bandar Lampung, Lampung Province, Indonesia. International Journal of Innovation, Creativity and Change 13, 323-336.

Soedibyo, A., 2012. Kepadatan Populasi Larva Aedes aegypti Pada Musim Hujan Di Kelurahan 
Petemon, Surabaya. Jurnal Kepadatan Pop.

Wahab, C.D.S., Wanti, 2019. Studi Keberadaan Jentik Aedes sp. Berdasarkan Karakteristik Kontainer dan Perilaku Pemberantasan Sarang Nyamuk Demam Berdarah Dengue di Kelurahan Oebobo. Oehonis: The Journal of Environmental Health Research 3, 147-152.

Wahyuningsih, N.E., Dharmana, E., Kusnawati, E., Sulistiawan, A., Purwanto, E., 2017. Kelimpahan Aedes spp. di kota semarang, purwokerto dan yogyakarta. Jurnal Entomologi Indonesia 5, 45.

Wanti, Menofeltus, D., 2014. Water container and the Aedes sp. larvae density in Endemic and Free Dengue Haemorrhagic Fever. Jurnal Kesmas 9, 171-178.
World Health Organization, 1997. Dengue Haemorrhagic Fever Diagnosis, Treatment, prevention and Control, second Edi. ed.

World Health Organization, 2011. Comprehensive guideline for prevention and control of dengue and dengue haemorrhagic fever.

Yulianti, E., 2013. Keefektifan Penggunaan Papan Informasi Pemberantasan Sarang Nyamuk (PSN) dalam Menurunkan Keberadaan Jentik Aedes aegypti. Unnes Journal of Public Health 2, 1-10. Yushananta, P., Ahyanti, M., 2014. Pengaruh Faktor Iklim Dan Kepadatan Jentik Ae.Aegypti Terhadap Kejadian DDB. Jurnal Kesehatan Lingkungan $\mathrm{V}, 1-10$. 